\title{
T-able: An Investigation of Habituating Moving Tables at Home
}

\author{
Jo HERSTAD ${ }^{\mathrm{a}, 1}$ Trenton W. SCHULZ ${ }^{\mathrm{a}, \mathrm{b}}$ Diana SAPLACAN ${ }^{\mathrm{c}}$ \\ ${ }^{a}$ Design of Information Systems Research Group (DESIGN), Department of \\ Informatics, University of Oslo \\ bNorwegian Computing Center \\ 'Robotics and Intelligent Systems Research Group (ROBIN), Department of \\ Informatics, University of Oslo
}

\begin{abstract}
This paper investigates the philosophical and designerly questions of how the concepts of familiarity, orientation, and habituation can be used to understand a selfmoving (semi-autonomous robot) table at home. Tables are familiar habituated objects in domestic settings for people with various abilities. We explore the idea of a selfmoving table through the lens of universal design. Phenomenology is applied to get a grip on ways of orienting and being oriented by such habituated familiar objects. Specifically, we investigate how the t-able is used as a telephone table, where the telephone is always charged and in a fixed place on the table. This is an attempt to make the telephone easier to use and relate to at home. The paper aims to inform future robots' design for the independently living elderly by designing robots mainly from natural materials, such as wood. We also discuss similarities and differences between the universal design of the built environment and ICT environments with this paper.
\end{abstract}

Keywords. Table, t-able, telephones, elderly, phenomenology, familiarity, orientation, habituation, universal design.

\section{Introduction}

What if a table could be called upon and bring me the telephone and carry a cup of tea? What if it could keep the phone always charged and in reach? Some elderly people posed this challenge in the Multimodal Elderly Care Systems (MECS) project [1], a project aiming at designing robots to support the independent living of the elderly. This paper reports from an exploration of ways of living with and relating to telephone tables at home. For this purpose, we have invited the elderly to take part in our study.

The structure of our surroundings at home shapes and guides our activities, and we structure and mold the surroundings to fit our lives and activities at home. We become familiar with and habituate objects in domestic settings over time. In this paper, we attempt to understand the process of habituating tables and telephones at home and how

${ }^{1}$ Jo Herstad, Department of Informatics, University of Oslo, Gaustadalléen 23B, 0373, Oslo, Norway; E-mail: jo.herstad@ifi.uio.no. 
important these objects are to increase an older person's agency and independence. With this understanding, we have, together with the elderly, made improvements and incremental design of a furniture look-alike robot, based on the telephone table, with the aim of supporting the autonomy of the elderly and hence their independence.

People arrange objects like tables, chairs, and telephones in a space to suit their needs and interest. These objects become habituated within life, into places and social relations over time [2]. Many elderly people have lived with telephones and telephone tables for decades, and they have habituated practices of using a stationary, landline telephone without any concern about charging it and searching for it since it is located at a fixed place on the table and powered through the land line.

We developed prototypes together with the elderly as a vehicle for exploring how the moving table can be used at home and support autonomy and independence. A phenomenological approach was taken to investigate and describe the use of the table, the interaction with the table, and the human-table relationship that is forming. The exploration illustrates the possibilities and challenges of universally designed selfmoving tables (aka robots) used by people living at home who are challenged when carrying things and moving around at home. This paper aims to understand how small tables can move by the command of the user to support everyday living at home. The research question addressed in this paper is: How can the concept of familiarity, orientation, and habituation be applied to understand and make sense of using a selfmoving table at home?

The rest of the paper is structured in the following way. In section 2, we continue with this study's background, where we present the research project briefly and give an overview of the current literature regarding robots for the independently living elderly. We base our motivation on the existing studies on the elderly's understanding and needs for the robots in the home and how they perceive those. After that, in section 3, we present our theoretical grounding from a phenomenological philosophical, and designerly perspective on domestic living. The idea of smartphones not having a fixed place and being lost in the home by the elderly is emphasized. This idea supports our proposed design: a telephone table for smartphones that can move semi-autonomously in the home, at the command of the user. Section 4 present our phenomenological approach briefly. Section 5 presents the design of the semi-autonomous telephone table, $t$-able: a telephone table for smartphones and for moving things around in the home, to enable elderly people to easily reach their smartphones, to avoid losing those within the home, and to support their independent living. The look and feel of the t-able and prototypes and some early tests are presented in this section. After that, in section 6, we present a short discussion. Section 7 concludes the paper.

\section{Background}

\subsection{The E-tikk Case}

E-tikk is the project name for both the $t$-able and the $s$-tool. The t-able is part of the MECS project [1], which investigates the possibilities and challenges with a robot safety alarm for the elderly. Instead of fitting the environment with sensors or letting the elderly wear body-worn safety alarms [3], the project has investigated the possibilities of keeping sensors on a robot to provide a safety alarm system. During workshops, user studies, and interviews with elderly people living at home, we have learned that the new 
technology's function is the most important. That is, what can the technology be used for? What added value or benefit the robot will give to the person living at home? One recurrent theme has been that of getting support with moving or bringing things within the home, such as a cup of tea, and keeping the telephone charged at all times and in place. We, therefore, developed a prototype that does this together with the elderly. The study also partially contributes to MECS' follow-up research project, the Vulnerability in Robot Society (VIROS) research project [4] that aims to investigate the safety, privacy, and security issues that robots pose.

\subsection{Motivation}

Thrun (2004) [5] classified robots into three main categories: industrial robots, professional service robots, and personal service robots. We are interested in the personal service robots. Earlier studies on the elderly understanding of the use of these types of robots in their homes showed that the technology was not adapted to their needs [6]-[8]. The study from Saplacan et al. (2020) [6] on the elderly's understanding of robots' concept showed that most of the elderly were mostly familiar with industrial robots and less personal service domestic robots. The authors explain how different types of robots were shown to the elderly, and while the researchers were interested mainly in developing a safety alarm robot for them, the elderly sought rather servant and robots that help them with home duties [6]. The authors explained how one of their elderly participants was particularly interested in the robots supporting their independent living by bringing them- or carrying their stuff around, such as food [6]. However, when asked about what the elderly thought about humanoid-looking robots, the elderly seemed reluctant [6]. They were not looking for zoomorphic or anthropomorphic looks in robots, neither for surveilling robots monitoring their health and activities, but for servant robots supporting them in their daily activities [5].

Further, several studies about robots used in the home [8] show that individuals are more used to personal service robots when it comes to robot vacuum cleaners. Nevertheless, elderly people seem to also be more familiar with such robots, as shown in [6]. Challenges still remain in the work that the elderly themselves, or their formal and informal care giver, need to do to fit the robot in their homes [8], [11], [12]. Articulation work (see [13], [14] for definitions) and nevertheless invisible work (see [15]-[21] for definitions and examples) seems to be necessary when introducing robots in the homes of the elderly. The motion of the robot, a moving object in the homes of the elderly, creates new forms of interaction between humans and technology. Motion as the feedback has been studied in some projects [8][22]. In general, the authors conclude that the technology's feedback should be proper, and it should not be absent [7]. If the technology lacks feedback or is improper, it seems to create difficulties for the elderly users in their interactions with the digital technology [7]. Despite these challenges, improving the interaction between humans and robots has been studied, having animation techniques as a starting point for designing better human-robot interaction [23] - [27]. Robot facilitation frameworks were developed [28], and robots used in a home setting, such as vacuum cleaners or lawn-mowers are tried to be understood [29].

Although some studies were already performed on the user of robots in the home, they remained a wonder for some. As we explained earlier, the elderly wish robots that are understandable for them, robots that they can manage easily, and are meaningful for them [6]. A table robot that can move around, and is built up from wood, similarly to an old stationary telephone table, can perhaps be more familiar for the elderly that do not 
master advanced technology well. Similar attempts were made earlier in designing for simplicity and prolonged the elderly's mastery of technology, as shown in [32]-[36]. However, these studies have their foci on stationary non-autonomous technologies, such as radios or telephone chargers. Therefore, this study is different because it looks at exploring semi-autonomous moving robotic telephone tables at homes, with a furniture wood-based look-like, that is modular and supports multi-modal interaction. These can perhaps be easier accepted in the homes of the elderly, considering that these can eventually be better integrated into their homes with the wood-like furniture look, rather than robots designed mainly out of plastic.

\section{Theoretical Grounding: Understanding Table as a Habituated Familiar Object in the Home}

"Let us return to the table. The table has a certain form, as we know. It is made of something. The matter and form of the table are dependent on histories of labor, which are concealed in and as the very thing of the table. The table is an effect of work, and it points to work in the very form that it takes. Different tables have different functions: We do things with them by performing actions upon them. If our object is a writing table, then our table is specifically adapted for convenience in writing or reading, perhaps something made with a sloping top and generally fitted drawer and compartments. " [37].

In homes, there are many objects, devices, and technologies adopted, adapted, and used by the dwellers. In turn, these things shape how we live at home. These objects are called habituated objects by Brereton [2], which indicates an active stance towards these things; they are actively taken into particular use - and sometimes modified to be fitted at home. These objects are incorporated into daily routines and habits at home, and they play an important role in shaping how we live our lives. One of such objects is the table.

\subsection{Tables in the Home}

But what does the word table mean? "The world table, we might note, is derived from the Latin word tabula, which primarily means a board, especially one used for games or writing. In its earliest English usages, table meant a surface, in particular a surface for writing, before the table became the name of the familiar article of furniture that we could describe as an object with a horizontal surface." (ibid). An example of a table with wheels is found in Figure 1. Even though it is equipped with wheels, this table is reported to have been in the same place for many years by the person living with it who is closer to 100 years of age than 80 .

Tables have been used, are used, and will be used by most people; from an early age - towards the end of life. We are familiar with tables and habituate tables into our homes by placing them, for example, where the morning light shines on them. We appropriate and accommodate tables for eating, working, and other activities at home. We move tables around, place them where they fit. Tables can be seen through the lens of activity, what we do with them, as an alternative to the view of a table as a "thing." For example, tables are used for sewing, playing cards, and eating [38]. 


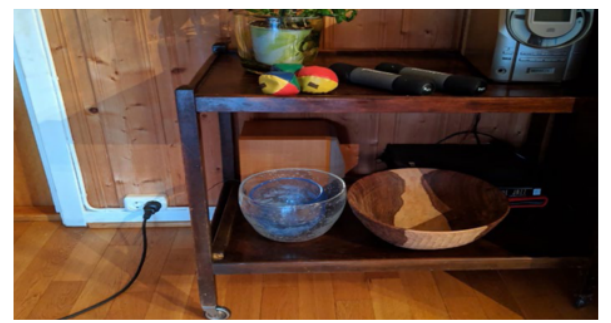

Figure 1. Table with wheels in a domestic setting. This table is used for displaying objects and for keeping exercise equipment visible when passing by.

\subsection{Telephone Tables}

Telephones are also often used in domestic settings and also habituated. "She prefers her phones arranged in space, rather than wearing one all the time, .....and because she doesn't want it constantly hanging on her." [2] It might be appropriate for some people to put the telephone in one specific place at home for different reasons. And the specific place is often called the telephone table, or the gossip table [39]. Examples of traditional telephone tables with a fixed telephone on top are found in Figure 2. Telephone tables also function as an ordering device, a fixed, central place for the (smart)phone. Interestingly, tables of content are also used as an ordering device; to put things, categories, and ideas into classes, divide stuff into classes, and group things according to labels, names, and categories. To place things on a board is itself a way to order things and objects, gather them around or give them a place near us, insight or out of sight.

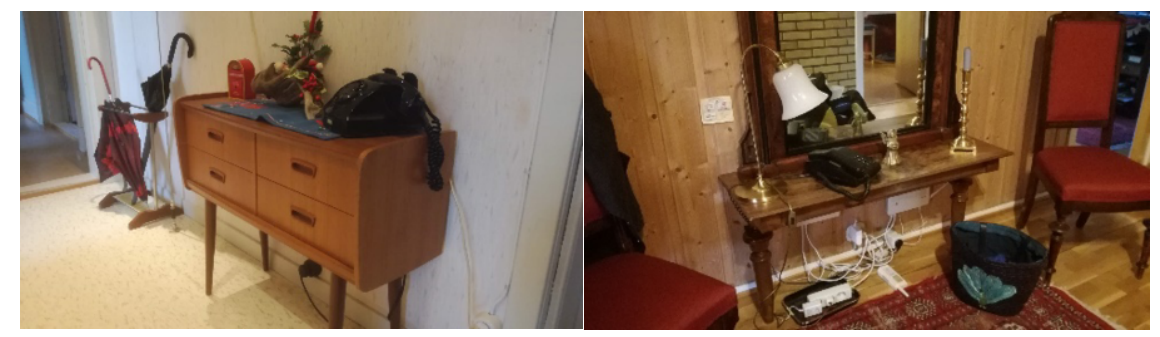

Figure 2. Two telephone tables with fixed land line phones

\subsection{The Place of the (Smart)Telephone in the Home}

Things tend to find their place at home after being there for a while, or else they are lying around scattered. "As she has appropriated these objects to her living needs, they have gradually found their places, and she has developed habits of use that support her independence and agency, connecting her to friends and services that she needs. In seeking to design to support the agency of the elderly, it is worth taking time to understand the way in which objects and technologies have been successfully adopted and habituated in an elderly person's life, and why some technologies fail to become habituated" [2]. One thing that lately has been uprooted from its fixed place is the telephone. For many decades, this device was in a fixed place at home, usually on top of a telephone table, and always powered. Now, many people are spending daily re- 
orienting themselves when doing battery management and searching for the phone at home - since it is no longer on the telephone table and hence occasionally lost.

For Heidegger, what makes the table what it is and not something else, is what the table allows us to do. The same can be said about the telephone; it is for us what it enables or allows us to do; make outgoing calls, receive incoming calls, talk and chat with other people. Similarly, the in-order-to when using the table is to study or share a meal. "What is there in the room at home is the table at which one sits to write, have a meal, sew or play. Everyone sees this right away, e.g., during a visit: It is a writing table, a dining table, a sewing table - such is the primary way in which it is being encountered in itself. This characteristic of to do something is not merely imposed on the table by relation and assimilating it to something else which it is not." [40] What the table is at home in everyday life is not primordially the height, mass, color, or other properties, characteristics, or measurements of the table, but what the table enables us to do; rest, write, talk together, etc. The telephone and the table together are primordially there to enable talking, perhaps taking some notes on the flat surface at the same time, feeling comfortable and safe that we know where it is and what it does.

\section{A Phenomenological Approach}

Why phenomenology? Phenomenology starts with the premise "to the things themselves" ( $Z u$ den Sachen selbst). It emphasizes the lived experience, the everyday life, and the lifeworld of the person living life at home. Phenomenology makes familiarity and orientation central in the very argument that we are always already directed toward, and in relationship with, each other and things. Also, the significance of nearness and proximity is central to phenomenology, what is ready-to-hand is seen as the primordial relationship in everyday-life. Within phenomenology, there is a nexus of things, equipment, and ways and structures in which the things show themselves - not primordially as isolated objects. This fits well with investigating and making sense of domestic settings, such as a telephone table and the telephone used in concert. Finally, the role of habituated and repeated actions and the way this shapes us and our lifeworld is central to phenomenology.

If we foreground the concepts of familiarity and orientation, then we can theorize the use of objects and things in familiar, domestic places. Foregrounding orientation and familiarity can be used to talk about nearness, proximity, and spatiality of use in appropriate ways for technologies we use and design.

\subsection{Framing Orientation from a Phenomenological Perspective}

Orientation involves different ways of registering the proximity of the surroundings, of objects, and others. Orientation shapes not only how we inhabit space but how we apprehend the world of shared inhabitants with objects and others [37]. Orientation is one of the primary conditions for the possibility of moving around going about our everyday life at home. Orientation gives us bearings and possibilities for moving. 


\subsection{Framing Familiarity from a Phenomenological Perspective}

Familiarity is a key term in phenomenology: “...orient myself both in and from my being already alongside a world which is familiar" [40]. Familiarity is what is given, what we are used to, what we know and relate to, and gives us the capacity to be oriented in this or that way. Familiarity is used to find our way around the home and to feel at home. We are familiar at home, know where things are and can orient and be oriented toward these things. Familiarity is also a key term in Human-Computer Interaction (HCI) literature; see, for example, Turner [41], who uses this concept to inform Universal Design, and Dourish [42] within the area of tangible interaction. Furthermore, the familiar is equated with the concept of intuitive, in the sense that what is experienced as intuitive is because we are familiar with it [43].

\section{Design the $t$-able}

This section presents the t-able with an s-tool look and feel, some early prototypes, its mechanics, and the tests made so far.

\subsection{T-able with an S-Tool Design Look}

We are particularly interested in learning about the use of the stool (krakk in Norwegian) in domestic settings. The stool is a versatile object; it is a jack-of-all-trades of homes and can be used as a chair, side table, telephone table, footrest - and for reaching the top of the shelf by standing on it. The stool is proved useful for all age groups, genders, and people with varied abilities, in different stages of life and a variety of situations.

One may argue, with its low set of requirements, that a stool is universally designed. In contrast to more specialized objects, like chairs, dining tables, and ladders, the stool, with its smaller size, is flexible and adaptable to more users and use situations. It is a humble, versatile object that sees many different uses. In the following sections, we will describe the stool used as a telephone-table. We have named the table t-able, an s-tool that is used for keeping the telephone charged and in place.

The stool is relatively small, so it can hold smaller items, such as a telephone, books, or a cup of tea. This is what the table does or assists with, keeping things on the flat surface on top. In addition, since it is relatively small, it can easily be moved around to different places in the home, reconfiguring the home on the fly as it were. This two inorder-to we are familiar with are the stool is used in-order-to holds things, and it is used in-order-to be placed where it is of use as a foot-stand, for example.

\subsection{Prototypes}

In an earlier article [44], we described the t-able. It was made in three iterations, illustrated in the pictures below. All prototypes were made from various types of wood, wheels, and control mechanisms. The top surface is around $40 \times 40 \mathrm{~cm}$, and the height is about $40 \mathrm{~cm}$. It is made rugged so that it is also possible to sit on top of it (maximum weight $200 \mathrm{~kg}$ ). The maximum speed is set to $1.3 \mathrm{~m} / \mathrm{s}$ for keeping the movement safe in the home. A first prototype is seen in Figure 3. For the specific use as a telephone table, the prototype was fitted with a place for charging the telephone and for keeping writing 
equipment at hand. This is illustrated in Figure 3 (center). The t-able is fitted with a battery that both power the engines for driving the table and the charging of the telephone on top. The battery is then charged when the t-able is connected to the central power system in the home at the charging station; for example, at one of the locations where it stands for longer periods. One version of the prototype is made with an extra tabletop that can be removed and used while sitting on a sofa or chair, using the sitters' legs to support the tabletop. This gives double the tablespace and works like a scriptorium.
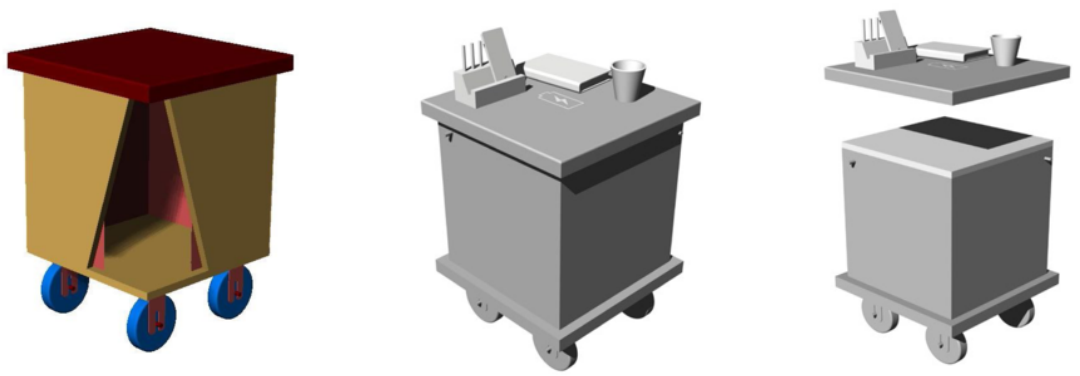

Figure 3. Left) Iteration 1 - T-able; center) T-able with telephone and charging; right) T-able with an extra tabletop extending the horizontal surface. [44]

Further development is needed to work on how control and steering of the table are to be done. Technically, the motor system controllers are interfaced both with an RF remote control, with Arduino microcontroller and plans are in place to use ROS (Robot Operating System) running on a PC. This opens the ability to interact with the table in various ways (voice, buttons, gestures), as well as fitting sensors to the table that will give input to the navigation, wayfinding, and obstacle detection of the table.

\subsection{Testing Out the Prototype}

The current prototype was tested so far in two homes, with both young (10-40) and old (80-100 years). No systematic testing or evaluation was done so far, but informal sessions were conducted where joy and excitement were expressed when the table was moving around in the home, sending away dirty dishes - and bringing the phone close at the command of the user.

Figure 4 a) shows a picture of one version of t-able when used for carrying tea and coffee. Inside the hull of the t-able are cups, spoons, and other equipment that needs to be moved from one place to the other at home. Figure $4 \mathrm{~b}$ ) shows an example from when the t-able was tested out in one of our participants' homes. 
a)

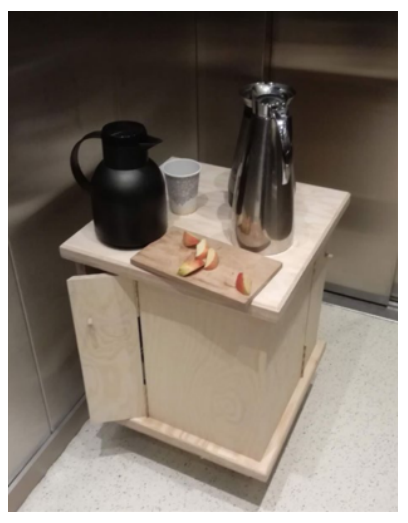

b)

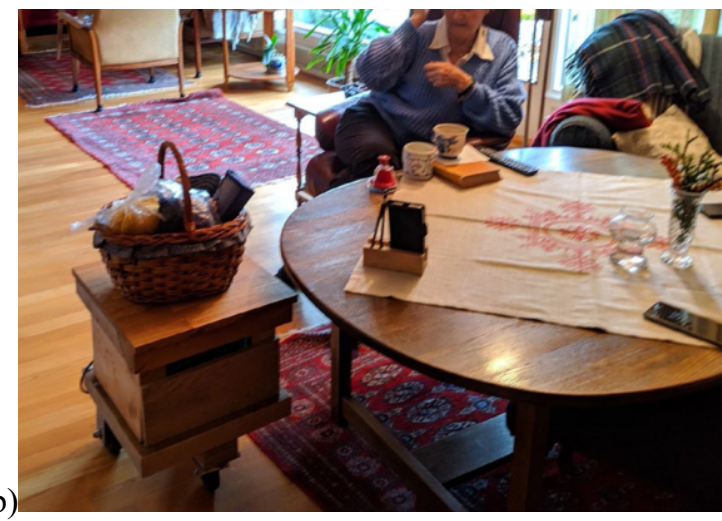

Figure 4. a) T-able holding things working as a tray on wheels. b) The t-able is remotely controlled by the user to bring it close or send it away. [44]

\section{Discussion}

This paper's objective was to understand how small tables can move by the command of the user to support everyday living at home. Thus, we have presented a prototype, the $t$ able, that can move by the command of the user. Many challenging questions are emerging with this prototype concerning interacting and using the table in sensible and meaningful ways. Further studies, tests, and co-design is needed in the quest for further developing functional prototypes. Inspiration to continue this work is found for example in: "In considering the design of technologies for the elderly, then, we might consider the qualities of objects themselves, how elderly configure them to suit their bodily needs and interests, and how these objects become habituated into life, place, and social relations over time. If we understand these habituated objects and how they increase the elderly persons' agency and independence, we might better understand how to design new internet of things' technologies that will become habituated and support independence" [2]. This gives the motivation to continue to investigate the use of habituated objects among the elderly. In-depth studies of how the current use of habituated objects at home, with, for example, interaction analysis, may give insights that can be used for further development of technology for the home.

\subsection{Moving Bodies and Things at Home}

Robots are entering domestic settings [9], [28], [45]-[47]. Vacuum cleaners, social robots, and lawnmowers that move around at home are examples of this. Also, some research prototypes are investigated for robot tables at home [48]. However, traditionally things do not move "by themselves" at home; the dweller moves them. An FM or DAB radio at home, for example, has the potential to be moved around while in use since it receives signals by radio waves. However, many people find it useful and appropriate to keep the radio where it is habitually used, at the bedside and the kitchen table. It is possible to move the radio around, but not necessary. The same goes for side tables with wheels; even though it is potentially possible to move the table around with the help of wheels, it is not necessary to move it around at all times. Many such tables are left 
somewhere, where they serve some need to hold things and occasionally move to other places.

What then about the mobile telephone? It is also a device that works with radio waves, so it is possible to move it around on the body - or keep it in the proximity of the body that is moving around at home. Where are mobile telephones found at home?

It is challenging to find answers to this. Studying the use of technologies in the home is challenging since it is a private place. Hence, we know little about what is really going on with smartphones at home. However, what we know is that there are different practices, habits, preferences, and uses of the phone at home [49]

One way to classify objects and how they move at home is:

- Some things are moving with the body: things kept on the body, in pockets, wrists.

- Some things are moved occasionally: on trays, books, food.

- Some things are seldom moved: kitchen bench, large tables, beds, walls.

The stool is used as a sitting device and a thing to hold and arrange other things. It is also a thing that is both used as a stationary device and a portable device. This makes it an interesting thing to investigate further and follow at home. As Appadurai suggests: "We have to follow the things themselves, for their meanings are inscribed in their forms, their uses, their trajectories." [50].

\subsection{The universal design of home environment}

Ronald Mace stated that "Universal design is the design of products and environments to be usable by all people, to the greatest extent possible, without the need for adaptation or specialized design" [51]. Both the telephone and the table, as isolated objects, are products that are usable by many people without the need for adaptation or specialized design. However, both for the elderly and in specific situations (broken leg), people find it difficult and challenging to move their own body around at home in concert with moving things around. All who have tried to walk supported by crutches and carry a hot cup of tea know this challenge. The situated abilities [51][52] vary across situations, activities, and times for everyone.

Seen as an isolated product, the mobile telephone might be evaluated as universally designed. However, when used in a home environment, it might be hard to locate and find. In addition to new orientation activities, the user needs to carry out power management and charging activities to make sure the telephone is powered. The telephone at home is part of a nexus of other equipment, such as the charger and the surface that it is kept on. The fixed place of the telephone table, that many elderly people are familiar with, gave peace of mind for many since both location-management and battery-management were minimal.

Are tables universally designed? Are telephones universally designed? These questions are about isolated objects, out of place and situated, habituated practical use. Much research has gone into both the fixed phone and mobile phone to get it universally designed [54]. However, in this paper, we were interested in the combined use of the phone and the table and how these two are used in concert, and it is a challenge to find support in the literature about this.

Together with the elderly, we re-designed the table as a tool, as something we do something with. To view furniture at home as tools or equipment (zeug), let us focus on what the thing enables us to do with it. One of the elderlies who used different stools 
suggested we design an s-tool out of it. The idea was to make something that enables independent living at home by re-designing a stool that is both a t-able and an s-tool.

\section{Conclusion}

The research question addressed in this paper was: How can the concept of familiarity, orientation, and habituation be applied to understand and make sense of using a selfmoving table at home? By attempting to use the concepts of familiarity, orientation, and habituation, we have conceptual lenses to get a better grip on what is going on in the domestic setting with respect to moving things and bodies. Daily, familiar, habituated life at home is situational, contingent, spontaneous, and indeed invisible from the outside.

\section{Acknowledgment}

This work was part of the Multimodal Elderly Care Systems (MECS) project funded by the Norwegian Research Council IKTPluss Program (Grant agreement no: 247697). The work also partially contributes to the Vulnerability in Robot Society (VIROS) research project funded by the Norwegian Research Council IKT Program (Grant agreement no: 288285). We would like to thank our project funders, partners, participants, and our DESIGN- and ROBIN colleagues. Moreover, we would like to express our thanks to Dawid Kulczko, Daniel Isaksen, Robin Pedersen, Mats Høvin, and Nicolas Ibacheta for making tables and telephones move and to Gro Skåland for asking critical questions on drafts of this paper.

\section{References}

[1] U. of O. Department of Informatics, "Multimodal Elderly Care Systems (MECS) - Department of Informatics," 2016. http://www.mn.uio.no/ifi/english/research/projects/mecs/ (accessed Nov. 06, 2016).

[2] M. Brereton, "Habituated objects: everyday tangibles that foster the independent living of an elderly woman," Interactions, vol. 20, no. 4, pp. 20-24, Jul. 2013, doi: 10.1145/2486227.2486233.

[3] S. Bedaf, G. J. Gelderblom, and L. de Witte, "Overview and Categorization of Robots Supporting Independent Living of Elderly People: What Activities Do They Support and How Far Have They Developed," Assist. Technol., vol. 27, no. 2, pp. 88-100, Apr. 2015, doi: 10.1080/10400435.2014.978916.

[4] University of Oslo, "Vulnerability in the Robot Society (VIROS) - Department of Private Law," 2019. https://www.jus.uio.no/ifp/english/research/projects/nrccl/viros/index.html (accessed Jan. 18, 2021).

[5] S. Thrun, "Toward a Framework for Human-robot Interaction," Hum-Comput Interact, vol. 19, no. 1, pp. 9-24, Jun. 2004, doi: 10.1207/s15327051hci1901\&2_2.

[6] D. Saplacan, J. Herstad, and Z. Pajalic, “An analysis of independent living elderly's views on robots A descriptive study from the Norwegian context," Proceedings of The International Conference on Advances in Computer-Human Interactions (ACHI). IARIA Conferences, Valencia, Spain, 2020.

[7] D. Saplacan and J. Herstad, "Fear, Feedback, Familiarity... How are These Connected? - Can familiarity as a design concept applied to digital feedback reduce fear?," Proceedings of The Eleventh International Conference on Advances in Computer-Human Interactions (ACHI). Mar. 2018.

[8] D. Saplacan and J. Herstad, “An Explorative Study on Motion as Feedback: Using Semi-Autonomous Robots in Domestic Settings:," Int. J. Adv. Softw., vol. 12, no. 1 \& 2, p. 23, Jun. 2019. 
[9] J. Forlizzi and C. DiSalvo, "Service Robots in the Domestic Environment: A Study of the Roomba Vacuum in the Home," in Proceedings of the 1st ACM SIGCHI/SIGART Conference on Human-robot Interaction, New York, NY, USA, 2006, pp. 258-265, doi: 10.1145/1121241.1121286.

[10] J. Forlizzi, "How Robotic Products Become Social Products: An Ethnographic Study of Cleaning in the Home," in Proceedings of the ACM/IEEE International Conference on Human-robot Interaction, New York, NY, USA, 2007, pp. 129-136, doi: 10.1145/1228716.1228734.

[11] D. Saplacan, J. Herstad, J. Tørresen, and Z. Pajalic, “A Framework on Division of Work Tasks between Humans and Robots in the Home,” Multimodal Technol. Interact., vol. 4, no. 3, Art. no. 3, Sep. 2020, doi: 10.3390/mti4030044.

[12] R. Soma, V. D. Søyseth, M. Søyland, and T. W. Schulz, "Facilitating Robots at Home: A Framework for Understanding Robot Facilitation," in 978-1-61208-616-3, Rome, Italy, 2018, pp. 1-6, Accessed: Mar. $\quad 206, \quad$ [Online]. Available: https://www.thinkmind.org/index.php?view=article\&articleid=achi_2018_1_10_20085.

[13] A. Strauss, "The Articulation of Project Work: An Organizational Process," ${ }^{-}$Sociol. Q., vol. 29, no. 2 , pp. 163-178, 1988, [Online]. Available: https://www.jstor.org/stable/4121474.

[14] L. Suchman, "Supporting articulation work," in Computerization and Controversy (2Nd Ed.), R. Kling, Ed. Orlando, FL, USA: Academic Press, Inc., 1996, pp. 407-423.

[15] D. Allen, The Invisible Work of Nurses : Hospitals, Organisation and Healthcare. Routledge, 2014.

[16] L. Bishop, "Visible and Invisible Work: The Emerging Post-Industrial Employment Relation," Comput Support. Coop Work, vol. 8, no. 1-2, pp. 115-126, Feb. 1999, doi: 10.1023/A:1008684030375.

[17] Y. Chen, K. Cheng, C. Tang, K. A. Siek, and J. E. Bardram, "The Invisible Work of Health Providers," interactions, vol. 21, no. 5, pp. 74-77, Sep. 2014, doi: 10.1145/2645645.

[18] R. Cross, S. P. Borgatti, and A. Parker, "Making Invisible Work Visible: Using Social Network Analysis to Support Strategic Collaboration," Calif. Manage. Rev., vol. 44, no. 2, pp. 25-46, Jan. 2002, doi: $10.2307 / 41166121$.

[19] I. Hampson and A. Junor, "Invisible work, invisible skills: interactive customer service as articulation work," New Technol. Work Employ., vol. 20, no. 2, pp. 166-181, 2005, doi: 10.1111/j.1468005X.2005.00151.x.

[20] K. Ehrlich* and D. Cash, "The Invisible World of Intermediaries: A Cautionary Tale," Comput. Support. Coop. Work CSCW, vol. 8, no. 1, pp. 147-167, Mar. 1999, doi: 10.1023/A:1008696415354.

[21] E. Hatton, "Mechanisms of invisibility: rethinking the concept of invisible work," Work Employ. Soc., vol. 31, no. 2, pp. 336-351, Apr. 2017, doi: 10.1177/0950017016674894.

[22] D. Saplacan and J. Herstad, "A Quadratic Anthropocentric Perspective on Feedback - Using Proxemics as a Framework," Conference Proceedings of BritishHCI 2017. Sunderland, U.K., Jul. 03, 2017, Accessed: Jul. 19, 2017. [Online]. Available: http://hci2017.bcs.org/wp-content/uploads/46.pdf.

[23] T. Schulz, J. Torresen, and J. Herstad, "Animation Techniques in Human-Robot Interaction User Studies: A Systematic Literature Review,” ACM Trans Hum-Robot Interact, vol. 8, no. 2, p. 12:1-12:22, Jun. 2019, doi: 10.1145/3317325.

[24] J. Herstad, R. Soma, S. Hovde, T. Schulz, D. Saplacan, and G. Verne, "When things move; human use and interaction with moving computers," ACM. CHI 2019 Extended Abstracts, Glasgow, Scotland, U.K., May 04, 2019.

[25] T. Schulz, J. Herstad, and J. Torresen, "Moving with Style: Classifying Human and Robot Movement at Home," in ACHI 2018, The Eleventh International Conference on Advances in Computer-Human Interactions, Mar. 2018, pp. 188-193, Accessed: Mar. 23, 2018. [Online]. Available: http://www.thinkmind.org/index.php?view=article\&articleid=achi_2018_10_20_20053.

[26] T. Schulz, J. Herstad, and J. Torresen, "Classifying Human and Robot Movement at Home and Implementing Robot Movement Using the Slow In, Slow Out Animation Principle," Int. J. Adv. Intell. Syst., vol. 11, no. 3 and 4, pp. 234-244, Dec. 2018, Accessed: Feb. 20, 2020. [Online]. Available: https://www.thinkmind.org/index.php?view=article\&articleid=intsys_v11_n34_2018_10.

[27] T. Schulz, P. Holthaus, F. Amirabdollahian, K. L. Koay, J. Torresen, and J. Herstad, "Differences of Human Perceptions of a Robot Moving using Linear or Slow in, Slow out Velocity Profiles When Performing a Cleaning Task," presented at the The 28th IEEE International Conference on Robot \& Human Interactive Communication (RO-MAN 2019), New Dehli, India, 2019, doi: 10.1109/ROMAN46459.2019.8956355.

[28] A. Rossi, K. Dautenhahn, K. L. Koay, and J. Saunders, "Investigating Human Perceptions of Trust in Robots for Safe HRI in Home Environments," in Proceedings of the Companion of the 2017 ACM/IEEE International Conference on Human-Robot Interaction, New York, NY, USA, 2017, pp. 375-376, doi: 10.1145/3029798.3034822.

[29] T. Schulz, P. Holthaus, F. Amirabdollahian, and K. L. Koay, "Humans' perception of a robot moving using a slow in and slow out velocity profile," in Proceedings of the 14th ACM/IEEE International 
Conference on Human-Robot Interaction, Daegu, Republic of Korea, Mar. 2019, pp. 594-595, Accessed: Feb. 20, 2020. [Online].

[30] C. Bartneck, T. Kanda, O. Mubin, and A. Al Mahmud, "The perception of animacy and intelligence based on a robot's embodiment," in 2007 7th IEEE-RAS International Conference on Humanoid Robots (Humanoids 07), 2007, pp. 300-305, Accessed: Nov. 29, 2007. [Online].

[31] R. Soma and J. Herstad, "Turning Away from an Anthropocentric View on Robotics," in Envisioning Robots in Society - Power, Politics, and Public Space: Proceedings of Robophilosophy 2018 / TRANSOR 2018, vol. 311, M. Coeckelbergh, J. Loh, and M. Funk, Eds. Wien, Austria: IOS Press, 2018, pp. 53-62.

[32] S. G. Joshi, "Designing for Capabilities: A Phenomenological Approach to the Design of Enabling Technologies for Older Adults," 2017, Accessed: Nov. 02, 2017. [Online]. Available: https://www.duo.uio.no/handle/10852/58738.

[33] S. G. Joshi, "Designing for Experienced Simplicity. Why Analytic and Imagined Simplicity Fail in Design of Assistive Technology," Int. J. Adv. Intell. Syst., vol. 8, no. 3 and 4, pp. 324-338, Dec. 2015, Accessed: Jul. 28, 2017. [Online]. Available: https://www.thinkmind.org/index.php?view=article\&articleid=intsys_v8_n34_2015_9.

[34] S. G. Joshi, "Designing for Experienced Simplicity. Why Analytic and Imagined Simplicity Fail in Design of Assistive Technology," Int. J. Adv. Intell. Syst., vol. 8, no. 3 and 4, pp. 324-338, Dec. 2015, Accessed: $\quad J u l . \quad 2017 . \quad$ [Online]. Available: https://www.thinkmind.org/index.php?view=article\&articleid=intsys_v8_n34_2015_9.

[35] S. G. Joshi and H. Bråthen, "Supporting new interactions with past experiences anchored in materials," IADIS International Journal on Computer Science and Information Systems, vol. 2, 11 vols. pp. 74 89, 2016, Accessed: Jul. 28, 2017. [Online]. Available: http://www.iadisportal.org/ijcsis/papers/2016190206.pdf.

[36] S. G. Joshi and T. Bratteteig, "Designing for Prolonged Mastery. On involving old people in Participatory Design," Scand. J. Inf. Syst., vol. 28, no. 1, Jul. 2016, [Online]. Available: http://aisel.aisnet.org/sjis/vol28/iss1/1.

[37] S. Ahmed, Queer Phenomenology. Orientations, Objects, Others. Duke University Press, 2006.

[38] M. Heidegger, Being and time. Oxford, U.K.: Blackwell Publishers Ltd, 1967.

[39] C. S. Fischer, America calling: a social history of the telephone to 1940. Berkeley Oxford: University of California Press, 1992.

[40] M. Heidegger, Ontology: The Hermeneutics of Facticity. Indiana University Press, 1999.

[41] P. Turner, "Being-with: A study of familiarity," Interact. Comput., vol. 20, no. 4, pp. 447-454, Sep. 2008, doi: 10.1016/j.intcom.2008.04.002.

[42] P. Dourish, Where the action is; the foundations of embodied interaction. Boston: MIT press, 2001.

[43] J. Raskin, "Viewpoint: Intuitive Equals Familiar," Сотmun ACM, vol. 37, no. 9, pp. 17-18, Sep. 1994, doi: $10.1145 / 182987.584629$.

[44] D. Saplacan, J. Herstad, and T. Schulz, "T-ABLE - The Robotic Wood Table: Exploring situated abilities with familiar things," Int. J. Adv. Intell. Syst., vol. 13, no. 3 \& 4, Dec. 2020, [Online]. Available: https://www.iariajournals.org/intelligent_systems/index.html.

[45] E. Cha, J. Forlizzi, and S. S. Srinivasa, "Robots in the Home: Qualitative and Quantitative Insights into Kitchen Organization," in Proceedings of the Tenth Annual ACM/IEEE International Conference on Human-Robot Interaction, New York, NY, USA, 2015, pp. 319-326, doi: 10.1145/2696454.2696465.

[46] D. A. Norman, "Robots in the Home: What Might They Do?," Interactions, vol. 12, no. 2, pp. 65-, Mar. 2005, doi: $10.1145 / 1052438.1052473$.

[47] T. Schulz, J. Herstad, and H. Holone, "Privacy at Home: An Inquiry into Sensors and Robots for the Stay at Home Elderly," in Human Aspects of IT for the Aged Population. Applications in Health, Assistance, and Entertainment, Jul. 2018, pp. 377-394, doi: 10.1007/978-3-319-92037-5_28.

[48] D. Sirkin, B. Mok, S. Yang, and W. Ju, "Mechanical Ottoman: How Robotic Furniture Offers and Withdraws Support," in Proceedings of the Tenth Annual ACM/IEEE International Conference on Human-Robot Interaction - HRI '15, Portland, Oregon, USA, 2015, pp. 11-18, doi: $10.1145 / 2696454.2696461$.

[49] R. Ling and B. Yttri, "Nobody sits at home and waits for the telephone to ring: Micro and hypercoordination through the use of the mobile telephone," Perpetual Contact Mob. Commun. Priv. Talk Public Perform., Jan. 1999.

[50] A. Appadurai, Ed., The social life of things: commodities in cultural perspective, 11. print. Cambridge: Cambridge Univ. Press, 2013.

[51] M. F. Story, J. L. Mueller, and R. L. Mace, The Universal Design File: Designing for People of All Ages and Abilities. Revised Edition. Center for Universal Design, NC State University, Box 8613, Raleigh, NC 27695-8613 (\$24), 1998. 
[52] D. Saplacan, "Situated ability: A case from Higher Education on digital learning environments," in Lecture Notes in Computer Science, Springer, Ch. 19, vol. HCII 2020, M. Antona and C. Stephanidis, Eds. Springer Nature Switzerland, 2020, pp. 1-19.

[53] D. Saplacan, "Situated Abilities: Understanding Everyday Use of ICTs," Ph.D. Thesis, University of Oslo, Department of Informatics, Faculty of Mathematics and Natural Sciences, Oslo, Norway, 2020.

[54] O. Plos and S. Buisine, "Universal design for mobile phones: a case study," in CHI '06 Extended Abstracts on Human Factors in Computing Systems, Montréal, Québec, Canada, Apr. 2006, pp. 12291234, doi: 10.1145/1125451.1125681. 